4 Herpes simplex virus 1 inhibits phosphorylation of RNA polymerase II

\title{
CTD serine-7
}

6

$7 \quad$ Adam W. Whisnant ${ }^{1}$, Oliver Dyck Dionisi ${ }^{1}$, Arnhild Grothey ${ }^{1}$, Julia M. Rappold ${ }^{1}$, Ana Luiza

$$
\text { Marante }^{1} \text {, Sharada S. Subramanian }{ }^{1}, \text { Lars Dölken }^{1 *}
$$

$14{ }^{1}$ Institute for Virology and Immunobiology, Julius-Maximilians-University Würzburg,

15 Versbacher Straße 7, 97078, Würzburg, Germany

$17 *^{*}$ Corresponding Author

18 Email: lars.doelken@uni-wuerzburg.de (LD)

19

20 Key words: Herpes simplex virus 1; RNA polymerase II; C-terminal domain; phosphorylation; 


\section{Abstract}

Transcriptional activity of RNA polymerase II (Pol II) is orchestrated by posttranslational modifications of the C-terminal domain (CTD) of the largest Pol II subunit, RPB1. Herpes Simplex Virus type 1 (HSV-1) usurps the cellular transcriptional machinery during lytic infection to efficiently express viral mRNA and shut down host gene expression. The viral immediate-early protein ICP22 interferes with serine 2 phosphorylation (pS2) of the Pol II CTD by targeting CDK9. The functional implications of this are poorly understood. Here, we report that HSV-1 also induces a global loss of serine 7 phosphorylation (pS7). This effect was dependent on the expression of the two viral immediate-early proteins, ICP22 and ICP27. While lytic HSV-1 infection results in efficient Pol II degradation late in infection, we show that pS2/S7 loss precedes the drop in Pol II level. Interestingly, mutation of the RPB1 polyubiquitination site mutation $\mathrm{K} 1268$, which prevents proteasomal RPB1 degradation during transcription-coupled DNA repair, displayed loss of $\mathrm{pS2} / \mathrm{S} 7$ but retained much higher overall RPB1 protein levels even at late times of infection, indicating that this pathway mediates bulk Pol II protein loss late in infection but is not involved in early CTD dysregulation. Using $\alpha$-amanitin-resistant CTD mutants, we observed differential requirements for Ser2 and Ser7 for production of viral proteins, with Ser2 facilitating viral immediate-early gene expression and Ser7 appearing dispensable. Despite dysregulation of CTD phosphorylation and different requirements for Ser2/7, all CTD modifications tested could be visualized in viral replication compartments by immunofluorescence. These data expand the known means that HSV-1 employs to create pro-viral transcriptional environments at the expense of host responses. 


\section{Introduction}

Herpes simplex virus type 1 (HSV-1) is a large, double-stranded DNA virus present in

nearly two-thirds of the global population that is the causative agent of the common cold-

sore as well as severe skin lesions, life-threatening neonatal encephalitis, and a leading cause

of infectious blindness (1). HSV-1 is a paradigm for a virus which induces a profound host shutoff during productive infection by targeting multiple steps of RNA metabolism.

of heptapeptide repeats of the evolutionarily consensus sequence tyrosine-serine-prolineheptapeptide repeats, particularly with variations in the seventh amino acid position, are enriched in the more distal of the 52 mammalian CTD repeats. Each non-proline residue serves as a site of phosphorylation that together help coordinate every step in transcription, with numerous additional post-translational modifications having been described in both the CTD and other regions of RPB1 (3).

Within hours of entering a cell, HSV-1 globally inhibits multiple Pol II processes on host genes such as promoter clearance (4,5), promoter-proximal pausing $(6,7)$, and polyadenylation (8) while preserving these functions on viral genes. This selective permissiveness has been attributed to different mechanisms including bulk redirection of DNA-binding proteins to nucleosome-free viral DNA $(5,9)$ to regulation of specific activities 
70

Via its interaction with CPSF, the HSV-1 immediate early protein ICP27 induces the assembly of a dead-end 3' processing complex, blocking mRNA cleavage. However, 3'-end processing of viral (and a subset of host) transcripts is rescued by the RNA sequence-dependent binding/activator activity of the viral ICP27 protein (10). The viral protein ICP22 has also been shown to interact with Cyclin-dependent kinase 9 (CDK9) $(11,12)$ and lead to a decrease of phosphorylated CTD Ser2, regarded as a positive marker for transcriptional elongation (13). Pol II activity is also tightly regulated under conditions of abiotic stress. For instance, a failure of transcription termination has been shown under conditions of hypoxia (14); heat, osmotic, and oxidative stress (15-18); as well as in renal carcinoma (19). Under these conditions, the normal $3^{\prime}$ ends of mRNA are not formed and polymerases transcribe thousands of additional bases downstream of normal termination sites; termed disruption of transcription termination (DoTT), downstream of gene (DoG) transcription, or read-through of polyadenylation (polyA) sites / polyA read-through. Distinguishing which processes are directly regulated by viral proteins and which are disrupted by cellular stress responses becomes imperative to understand transcription during infection.

In this study, we sought to determine HSV-1-induced dysregulation of Pol II CTD modifications and their functional consequences in relation to other stressors. Besides the well-described loss of Ser2 phosphorylation (pS2), we report that HSV-1 infection of primary human fibroblasts also resulted in a global loss of Ser7 phosphorylation (pS7) by 8h postinfection (p.i.), which was not observed in cellular stress responses. Expression of the two viral immediate-early genes ICP22 and ICP27 was necessary to induce loss of pS7 and we provide additional evidence that loss of CTD hyperphosphorylation is separate from bulk RPB1 degradation. Though phosphorylation of both residues is reduced in infection, alanine substitution of Ser7 had no visible impact on viral gene expression while Ser2 substitution 
94 was detrimental. Despite Ser7 being dispensable for viral gene expression, its phosphorylation, as well as every other CTD modification examined, could be visualized in viral replication compartments in primary cells. These findings expand the known means of transcriptional regulation by a major human pathogen.

98

99 Results

\section{Quantification of CTD Modifications During Conditions of polyA}

\section{Read-through}

As transcriptional termination is coordinated in part by CTD phosphorylation, we first determined whether a common disruption of RPB1 modifications occurs under conditions of heat stress $\left(44^{\circ} \mathrm{C}, 2\right.$ hours [h]), HSV-1 infection (strain 17syn+, MOI=10, 8h), osmotic stress $(80 \mathrm{mM} \mathrm{KCl}, 1 \mathrm{~h})$ or oxidative stress induced by $0.5 \mathrm{mM}$ sodium arsenite for $1 \mathrm{~h}$ in primary human foreskin fibroblasts. Timepoints for each condition were based on use in previous studies. Both heat stress and HSV-1 infection induced accumulation of intermediately phosphorylated RPB1 as seen by relative migration in SDS-PAGE (Pol Ili, Fig 1A). While all phospho-serine signals were strongly enriched on hyperphosphorylated Pol II (Ilo), the signals of $\mathrm{Y} 1$ and $\mathrm{T} 4$ phosphorylation and $\mathrm{K} 7 \mathrm{di} /$ tri-methylation more closely correlated to the relative abundance of the different migrating forms of RPB1 in each sample. Interestingly, the

114 phospho-serine signals for heat stress and HSV-1 infection migrated below the

115 hyperphosphorylated Ilo signals in mock samples, but remained above the predominate Ili signal for total RPB1 (see E1Z3G in green in S1A Fig). 

modifications, and vinculin as a housekeeping control. Signal for each CTD modification was measured, normalized to the signal for total RPB1 on the same blot, and plotted relative to levels in untreated cells. (B) Mean values of three biological replicates with standard deviations are plotted. Statistically significant differences to mock are indicated as $* p<0.05$, $* * \mathrm{p}<0.01$ on the same blot. For all stress conditions, a slight (20-30\% on average) reduction in tyrosine 1 phosphorylation (pT1) was observed relative to mock (Fig 1B). Surprisingly, threonine 4 phosphorylation (pT4), which predominately accumulates around transcription termination sites and is involved in $3^{\prime}$-end formation $(21,22)$, remained unaffected in all conditions; as did serine 5 phosphorylation (pS5) and K7 di/tri-methylation levels (K7me). HSV-1 infection was the only condition observed to heavily impact CTD modifications, causing a $~ 70 \%$ reduction in $\mathrm{pS} 2$, as previously described, and a $\sim 50 \%$ loss of serine 7 phosphorylation (pS7). 
panel of different CTD phospho-serine antibodies for each serine residue on the same

Fig. Of five antibodies tested for pS2, all showed a reduction of pS2 in HSV-1 infection, while three antibodies showed a $\sim 2$-fold reduction for heat and two for salt stress (S1A Fig). and Drosophila cells (27-29), with a decrease of pS2 and pS5 reported in mouse cells (30).

One of three antibodies showed increases of pS5 levels for heat stress and oxidative stress, while one of two antibodies showed a reduction of pS7 in all conditions (S1 Fig). Overall, these data indicate that there that HSV-1 causes a loss of two major CTD modifications while there is no major CTD modification indicative of general stress responses beyond a slight reduction of $\mathrm{pY} 1$. Dephosphorylation of $\mathrm{Y} 1$ is directly involved in recruiting termination factors in yeast (31), and mammalian RPB1 mutants where the distal 3/4 of Y1's are phenotype during cellular stress.

\section{Loss of CTD serine 7 phosphorylation in HSV-1 infection is due to}



prevent viral late gene expression, demonstrated that viral late gene products are not required for the observed pS7 loss (Fig $2 A, B$ ), with a steady decrease beginning at $4 \mathrm{~h}$ p.i. To specifically test immediate-early (IE) genes, a cycloheximide reversal assay was performed. In this assay, cells are infected and then treated with cycloheximide to allow transcription - but not translation - of the five viral IE genes, which do not require synthesis of new viral proteins additional $8 \mathrm{~h}$ to allow translation of the accumulated viral IE mRNA but prevent transcription of early and late genes. In these conditions however, a noticeable decrease in all forms of Pol II due to degradation was observed (S2A Fig). This is in line with previous reports using actinomycin D suggesting that the normal virally induced CTD modifications or even RPB1 stability require ongoing transcription (33). proteins ICP22 and ICP27. (A) Human foreskin fibroblasts (HFF) were infected with HSV-1 17syn+ with and without DNA replication inhibitor phosphonoacetic acid (PAA) and total protein harvested at given timepoints. Levels of CTD serine 7 phosphorylation (pS7) relative to total RPB1 were quantified by Western blotting. (B) Means of at least three replicates relative to the corresponding mock-infected sample plotted with standard deviations. (C) HFF cells infected with HSV-1 KOS treated with PAA or KOS-derived mutants lacking the combinations of immediate-early genes indicated in the table in the bottom right. White bars indicate removal of irrelevant samples. Total protein was harvested at $8 \mathrm{~h}$ p.i. and pS2/7 levels 
determined by Western blot. (D) Quantification of phospho-serine levels normalized to total

RPB1. Means of three replicates normalized to mock-infected samples with PAA with standard error are plotted, values from KOS are from PAA-treated samples. Statistically significant differences to mock are indicated as $* p<0.05, * * p<0.01$. to pS2, which accumulated to higher levels without ICP22 compared to the wild-type strain, no individual viral IE gene seemed sufficient to account for the loss of pS7 (S2B Fig). The addition of PAA with these mutants prevented some of the pS7 loss, indicating that viral late genes and/or DNA replication, though not required, can facilitate CTD remodeling as previously described $(12,13,34)$. Importantly, no loss of pS7 was observed upon infection with a mutant virus whose genome is not trafficked to the nucleus due to the removal of the nuclear localization signal in the UL36 protein (dNLS, Fig 2C,D). Therefore, viral tegument proteins delivered by the incoming virus particles are not sufficient to induce pS7 loss, as indicated by the retention of pS7 when using cycloheximide alone (Fig. S2A). genes were tested. It is important to note that viral gene expression by these viruses is restricted to the remaining four immediate early genes (ICP0, ICP22, ICP27 and ICP47.5). The strongest reduction ( 50\%) in pS7 was observed in viruses expressing both ICP22 and ICP27 
CDK9, while ICP27's impact on pS7 is less readily apparent. ICP27 is known to co-precipitate

with RPB1 $(35,36)$ and other transcription factors such as SPT5; the latter interaction facilitated by CDK9 activity (37). ICP27 has also been previously reported to reduce Ser2 phosphorylation in HeLa and RSF $(36,38)$-but not Vero (13)- cells. However, as the other immediate-early mRNAs exhibit less cytoplasmic accumulation without ICP27 (39), an effect on ICP22 expression cannot be ruled out for the impact on pS2. These data indicate that while loss of ICP27 did not alter ICP22-mediated effects on serine 2 phosphorylation in infected primary human fibroblasts, ICP22 and ICP27 work in a complementary manner to deplete serine 7 phosphorylation that does not require viral late gene expression. HSV-infected cells rapidly shuts down after the peak of viral gene expression around $8 \mathrm{~h}$ p.i. (40-42), associated with Pol II holoenzyme remodeling (43) and degradation of RPB1 itself at later timepoints (33). In addition to viral replication compartments, RPB1 localizes to virusinduced chaperone (VICE) domains $(36,38)$ which have been proposed to serve as sites of quality control for protein folding and/or complex assembly as they contain numerous chaperones and proteasome components $(44,45)$. Protease activity and different types of mono- and polyubiquitination have been detected in VICE domains, though it is not clear if all assembly sites for complicated higher-order protein structures (46). 
While the exact roles of VICE domains in regulating transcription are unknown,

232

233

234

235

236

237

238

239

240

241

242

243

244

245

246

247

248

249

250

251

252

proteasome inhibitors which block VICE domain formation $(36,38)$ were previously found to prevent the loss of pS2 (36), and we observed this for pS7 as well (Fig 3A). Efficacy of the proteasome inhibitors could be visualized by increased p53 levels and laddering indicating polyubiquitination, and for RPB1 specifically accumulation of a high molecular weight (MW) band likely corresponding to ubiquitinated RPB1 (38) and lower MW bands indicative of degradation products could be observed in both infected and uninfected cells (S3A Fig). Interestingly, the migratory shift of RPB1 from Ilo to Ili during gel electrophoresis could still be observed in infected cells even though treated samples had relatively equal levels of pS2 and pS7 as uninfected controls (S3B Fig). We are unable to measure the levels of ICP22 expression under these settings due to the lack of a commercial antibody, but previous work demonstrated that ICP22 expression is not altered by proteasome inhibition (47).

\section{Fig 3. Effects of proteasome inhibitors and RPB1 polyubiquitination mutants on HSV-1-}

induced RPB1 remodeling. (A) Human foreskin fibroblasts were infected with HSV-1 17syn+ and treated with indicated proteasome inhibitors for $8 \mathrm{~h}$ before collection of total protein and quantification of CTD Ser2 and Ser7 phosphorylation by Western blotting. Plotted are means of two replicates with standard deviations. (B-D) 293T parental wild-type (WT) and clonally derived RPB1 K1268R mutant cell lines were infected with HSV1(17+)-LoxCheVP26 and total RPB1 or phosphorylated CTD serine residues quantified by Western blotting. (B) Relative levels of CTD serine phosphorylation at $8 \mathrm{~h}$ p.i.; plotted are three individual replicates with longest lines indicating means and shortest standard error ranges. (C) Representative Western blot of RPB1 levels in uninfected (Un.) 293T WT and RPB1 K1268R or cells infected 

phosphorylation in the cell. via polyubiquitination of RPB1, leading to release of RPB1 from DNA and subsequent degradation. Recent work demonstrated that this polyubiquitination occurs on a single lysine, K1268; and while other sites of monoubiquitination exist, mutation of this single lysine to arginine completely prevented degradation of RPB1 after UV irradiation (48). Two monoclonal cell lines bearing the RPB1 K1268R mutation exhibited an equal loss of serine 2 almost exclusively as a lower MW smear while RPB1 K1268R mutant cells exhibited a 50\% retention in total RPB1 protein (Fig 3C,D). Visualization of mCherry fused to the viral late gene VP26 indicated that viral gene expression at 8 and $24 \mathrm{~h}$ was comparable across all cell lines 
demonstrates that the RPB1 ubiquitination pathway active during DNA damage is not involved in CTD remodeling during the bulk of viral gene expression, but may degrade Pol II at later times during virion assembly and genome packaging. It is possible that the $50 \%$ reduction of RPB1 in the K1268R cells may not be due to degradation, but standard protein turnover coupled with the virus-induced shutoff of host mRNA translation as RPB1 is reported to have a half-life of $6 \mathrm{~h}$ in mammalian cell lines (49). Virus production in these cells was measured to determine if RPB1 degradation facilitates productive infection and virus release, however the two clones bearing the K1268R mutation gave differential phenotypes as the mutant clone D12 produced viral progeny equal to WT cells while the E2 clone was consistently $\sim 5$-fold lower than the other two cell lines (S5C Fig). Overall, these data indicate that while proteasome-dependent pathways are active in CTD remodeling during lytic HSV-1 infection, they are separate from transcription-coupled repair and precede the bulk degradation of RPB1.

\section{Herpesviral DNA recruits, but does not require, all CTD modifications} though HSV-1 infection reduced global pS2 and pS7 levels, these modifications were still 
Fig 4. Co-localization of RPB1 CTD modifications with viral replication compartments.

Human foreskin fibroblasts were infected with HSV-1 strain 17syn+ for 8 h before fixation. modifications. $p=$ phosphorylation, me=methylation.

Previous studies have shown that chemical inhibition of CDK9 reduces herpesviral gene expression $(51,52)$, indicating that HSV-1 still requires some degree of phosphorylation on the CTD and/or other transcription factors. We decided to investigate the requirements of viral genes for CTD serines 2 and 7 using an amanitin-based RPB1 replacement assay. HEK293T cells were co-transfected with a plasmid expressing the blue fluorescent protein Azurite as a visual control for transfection efficiency and vectors expressing $\alpha$-amanitin-resistant, HAtagged RPB1 constructs $(53,54)$ containing either a wild-type (WT) CTD or mutant CTDs. The mutations are non-phospho-accepting alanine substitutions in place of serines 2 or 7 (S2A and S7A, respectively) or the phospho-serine mimic glutamic acid at serine 7 (S7E). After $24 \mathrm{~h}, \alpha-$ amanitin was added to degrade endogenous RPB1 for an additional 24h, followed by infection with fluorescent HSV-1 expressing eYFP-ICPO as an immediate-early gene marker and gCmCherry as a late gene marker (55). As shown in Fig 5, detectable levels of IE and late genes could be visualized in cells with replaced WT CTD at $24 \mathrm{~h}$ p.i., albeit at substantially lower levels than amanitin-untreated cells, but not with empty pcDNA3 vector control. As expected, both early and late viral gene expression was reduced with CTD S2A mutants. In contrast, S7A mutations expressed both classes viral genes equally well as the WT CTD. Interestingly, the 
324

325

326

327

328

329

330

331

332

333

334

335

336

337

338

339

340

341

342

though this is likely due to reduced recruitment and/or 3'-end processing (54) as even Azurite expression was reduced. Western blotting for the plasmid-expressed, HA-tagged RPB1 verified that expression of the exogenous RPB1 mutants were comparable across conditions (S6 Fig). These data demonstrate that while viral DNA localizes all major CTD modifications, not all are required for viral late gene expression. In the case of CTD serine 7 , the amino acid itself appears completely dispensable during lytic infection.

Fig 5. CTD serine 2, but not serine 7 , is required for efficient viral gene expression. HEK293T cells were co-transfected with a construct expressing Azurite blue fluorescent protein as a transfection marker and plasmids expressing amanitin-resistant RPB1 with wild-type (WT) or indicated mutant CTDs, or the control vector pcDNA3 lacking any polymerase. The next day, $\alpha$-amanitin was added to degrade endogenous RPB1 for $24 \mathrm{~h}$ followed by infection with an eYFP-ICPO-/gC-mCherry-expressing HSV-1. Live-cell imaging was performed at 24h p.i. All images were acquired with the same settings, with infection of untransfected, amanitinuntreated cells included as a reference for the relative level of viral gene expression. PC: phase contrast, S2A: serine 2 to alanine, S7A: serine 7 to alanine, S7E: serine 7 to glutamate. Scale bars indicate $100 \mu \mathrm{m}$.

\section{Discussion}

Post-translational modification, particularly phosphorylation, of the RPB1 CTD is at the core of numerous transcriptional responses. Release of CDK9 from the 7SK snRNP and resulting transcription P-TEFb-dependent genes greatly impacts mammalian cell survival during genotoxic stress (56) and interferon responses during viral infection (57). As 
phosphorylation of multiple CTD residues (namely Tyr1, Ser2, and Thr4) are involved in

termination of mammalian protein-coding genes, we reasoned that there could be a core dysregulation of the CTD code in response to stress. However, we observed no major changes in the CTD shared across all conditions tested. Both HSV-1 infection and heat stress induced the intermediate-migrating Ili form of RPB1, while only HSV-1 showed a consistent loss of pS2 and pS7 with all antibodies tested. To avoid antibody bias, future work should implement mass spectrometry-based assays $(2,58)$ to quantify the phosphorylation states of the lli forms of RPB1 in heat stress and HSV-1 infection. Though different challenges to cellular homeostasis can have similar global impacts on gene expression, particularly in regards to inhibiting polyadenylation, our data demonstrate that this is not due to a common, global disruption of the RPB1 CTD. ICP22 and ICP27 in the loss of pS7. While ICP22's known ability to regulate CDK9 can account for this protein's contribution, ICP27 may work by other means. Beyond simply supporting expression of other viral genes, ICP27 binds directly to RPB1 and could disrupt downstream interactions and phosphorylation. Both ICP22 and ICP27 have been implicated in VICE domain formation, and it is possible that RPB1 may interact with proteins in these domains that limit its ability to be phosphorylated. Though VICE domains contain numerous components involved in protein misfolding and degradation, we favor the view that they facilitate RPB1 remodeling and trafficking over proteolysis as we do not observe a major decrease in RPB1 levels until well after the decrease in pS2/7. Our data supports previous observations that ongoing viral transcription is required for CTD remodeling, as even relatively weak expression of immediate early genes can trigger 
degradation pathway is likely separate from the one during DNA damage as it occurs when transcription is chemically inhibited. We observed that degradation of RPB1 mediated by polyubiquitination of K1268 is not involved in the loss of pS2/7, but stabilizes RPB1 $24 \mathrm{~h}$ p.i.

This suggests that there are multiple degradation pathways triggered by HSV-1 at different stages of infection and reside in a balance with ongoing viral transcription or trafficking between VICE domains and replication compartments (RCs). Degrading Pol II on viral DNA may preserve genomes in settings of abortive infection by halting the production of viral antigens or innate immune triggers like double-stranded RNA, or help maintain latency with leaky transcription. It will be of interest to experimentally determine ubiquitination sites at early and late timepoints of HSV-1 infection by mass spectrometry to better understand how the proteasomal machinery is involved with viral transcription cycles and shuttling of RPB1 between the various nuclear compartments. reduced transcriptional elongation rates of cellular mRNA as a means of countering host responses (11), and even to regulate viral genes themselves (59). However, chemical inhibition of CDK9 also reduces viral gene expression and our data with S2A mutants recapitulates this phenotype, indicating a beneficial role for at least intermediate pS2 levels in regards to viral genes. Contrary to this, polymerases with S7A mutations expressed viral proteins comparable to the WT CTD, demonstrating that the entire CTD code is not required

390 for herpesviral gene expression despite the fact that all modifications we could test are 391 localized to viral replication compartments. The presence of pS7 on the viral genome may therefore be a consequence of recruiting kinases for their other, necessary phosphorylation events or serve to sequester transcription factors away from host chromatin. We also cannot rule out the possibility that Ser7 regulation may be more impactful during reactivation from 
latency over lytic infection or during inflammatory responses. Indeed, inhibition of another

Ser7 kinase, CDK7, has been shown to reduce cytokine release and inflammation $(60,61)$, but

more work is required to determine contributions from Ser7 vs. other CDK7 targets, especially

CTD Ser5. expected to alter the abundant pool of mature splicing factors, and most viral genes are has direct roles in regulating protein-coding genes, and knockdown of its catalytic subunit recapitulates termination defects on a subset of host mRNAs disrupted during osmotic stress (64), though our previous work implicates ICP27-CPSF interactions as the primary determinant during HSV-1 infection (10). Work is ongoing to analyze the role of integrator in HSV-1 infection. The reduction of pS7 could also result in more subtle, global consequences on host gene expression as pS7 has been proposed to suppress cryptic transcription (65) as

411 well as stimulate Ser2 phosphorylation by CDK9 and CDK12 $(66,67)$. Our future efforts will 412 involve mapping the genomic locations of $\mathrm{pS} / 7$ during infection by ChIP/mNET-seq to better understand the impacts of herpesviral-induced CTD remodeling.

\section{Materials and Methods}

\section{Cell lines and viruses}



$\mathrm{CO}_{2}$-enriched incubator. derived strains KOS and HSV1(17+)-LoxCheVP26 (73) were propagated on BHK-21 cells as well and titered on F06 cells.

All infections, except those for virus growth curves, were performed with an $\mathrm{MOI}$ of 10 by 
inoculum was replaced with culturing medium or medium containing concentrations of

compounds described below.

\section{Stress and drug treatments}

for $2 \mathrm{~h}$ at $44^{\circ} \mathrm{C}$. Salt stress and oxidative stress were initiated by adding $\mathrm{KCl}$ or sodium arsenite timepoint 0 and infected cells at 8 h p.i.

$\mu \mathrm{g} / \mathrm{mL}$ when indicated. Bortezomib (Selleckchem \#S1013) was used at a concentration of

with equal volumes of DMSO vehicle used as control. Actinomycin D was used at $5 \mu \mathrm{g} / \mathrm{mL}$ and

\section{Western blotting}

A full description of antibodies is found in S1 Table. Total protein samples were

harvested by lysing cells directly in Laemmli buffer at given timepoints. Samples were acrylamide:bisacrylamide, and transferred overnight in tris-glycine buffer containing $20 \%$ water and blocked in tris-buffered saline with $0.1 \%(\mathrm{v} / \mathrm{v})$ Tween 20 (TBST) with $5 \%(\mathrm{w} / \mathrm{v})$ milk 
464

465

466

467

468

469

470

471

472

473

were washed in TBST, blocked for one additional hour, and secondary antibodies allowed to bind for one hour before final TBST washes and visualization on a LI-COR Odyssey Fc imaging system. Deviations from this procedure are indicated in the relevant figure legends.

Band densitometry was performed using Image Studio Light (LI-COR). Total RPB1 levels for each sample were normalized to vinculin signal on the same membrane. Signals for each CTD modification were normalized to total RPB1 levels on the same membrane. The relative ratios are compared to mock samples on the same membrane, which was set to 100\%. Statistical significance was determined using two-way ANOVA in GraphPad Prism.

\section{Immunofluorescence}

$3 \times 10^{4}$ HFF cells were seeded onto 8 well glass chamber slides (Ibidi \#80841). The following day, cells were infected at an $\mathrm{MOI}$ of 10 and fixed 8 h p.i. in $4 \%$ formaldehyde in PBS for 15 minutes. After washing in PBS, cells were incubated in permeabilization buffer $(10 \%$ [v/v] FBS, 0.5\% [v/v] Triton X-100, 250mM glycine, 1x PBS) for 10 minutes, then blocked for 1h in blocking buffer (10\% [v/v] FBS, $250 \mathrm{mM}$ glycine, 1x PBS). Primary antibodies were incubated overnight at $4^{\circ} \mathrm{C}$ in $10 \%(v / v)$ FBS and $1 x$ TBS. The secondary antibodies were incubated in $10 \%$ FBS in $1 x$ TBS for 1 h at room temperature with $1 \mu \mathrm{g} / \mathrm{mL}$ 4',6-diamidino-2phenylindole (DAPI). A full description of antibodies is found in S1 Table. Coverslips were washed in water before mounting them in medium containing Mowiol 4-88 and $2.5 \%(\mathrm{w} / \mathrm{v})$ 1,4-diazabicyclo[2.2.2]octane (DABCO). All steps before antibody binding were followed by three 5-minute washes in PBS, while TBS was used after antibody binding. Samples were imaged on a Zeiss LSM 780 where slices of $0.5 \mu \mathrm{m}$ were taken and intensities of each slice 
summed in Fiji (77) to produce the $2 \mathrm{D}$ images provided. Live-cell imaging of fluorescent viruses was performed on a Leica DMi8.

488

489

\section{RPB1 replacement assay}

490

$5 \times 10^{4}$ HEK-293T cells were seeded in poly-lysine-coated 48-well plates. The next day,

491

cells were transfected with 15ng of pLV-Azurite (gift of Pantelis Tsoulfas, Addgene \#36086)

492

and 250ng of vectors expressing HA-tagged, amanitin-resistant RPB1 constructs with the

493

mutant CTDs or pcDNA3 as a negative control via polyethylenimine (PEI). The WT and S2A

494

mutant are described in (53), the S7A and S7E mutants in (54). All RPB1 constructs were

generous gifts of Dirk Eick, LMU Munich. After 24h, media was exchanged for fresh growth

medium with $2.5 \mu \mathrm{g} / \mathrm{mL} \alpha$-amanitin for an additional $24 \mathrm{~h}$. Cells were infected with eYFP-

ICPO/gC-mCherry HSV-1 at MOI 10 as described above in serum-free medium for $1 \mathrm{~h}$. This

inoculum was removed and amanitin-containing growth medium reapplied until imaging $24 \mathrm{~h}$

p.i.

500

\section{Acknowledgements}

We would like to thank Dirk Eick for the mutant RPB1 vectors and methyl-CTD K7 antibody, cell lines, as well as Colin Crump and Beate Sodeik for fluorescent BAC viruses. This work was supported by the Deutsche Forschungsgemeinschaft (DFG grant D01275/6-1) and the

506 European Union (ERC-2016-CoG 721016-HERPES) to L.D. A.W.W. was the recipient of a

507 generous grant from the Alexander von Humboldt Foundation and the German Federal 508 Foreign Office. 


\section{Contributions}

511 A.W.W. and L.D. conceived and designed the experiments and wrote the paper. A.W.W.

512 performed the experiments with the help of O.D.D., A.G., J.M.R., A.L.M., and S.S.S.

513

514 References

515 1. Fields BN, Knipe DM (David M, Howley PM. Fields virology. Wolters Kluwer Health/Lippincott Williams \& Wilkins; 2013. 82 p.

517 2. Schüller R, Forné I, Straub T, Schreieck A, Texier Y, Shah N, et al. Heptad-Specific 2017 Aug 14];61(2):305-14. Available from:

http://www.ncbi.nlm.nih.gov/pubmed/26799765

521

3. Zaborowska J, Egloff S, Murphy S. The pol II CTD: New twists in the tail. Vol. 23, Nature Structural and Molecular Biology. Nature Publishing Group; 2016. p. 771-7.

4. Abrisch RG, Eidem TM, Yakovchuk P, Kugel JF, Goodrich JA. Infection by Herpes Sep 4];90(5):2503-13. Available from: http://www.ncbi.nlm.nih.gov/pubmed/26676778

5. Dremel SE, Deluca NA. Herpes simplex viral nucleoprotein creates a competitive transcriptional environment facilitating robust viral transcription and host shut off. Elife. 2019 Oct 1;8.

6. Birkenheuer CH, Danko CG, Baines JD. Herpes Simplex Virus 1 Dramatically Alters 
Loading and Positioning of RNA Polymerase II on Host Genes Early in Infection.

7. Birkenheuer $\mathrm{CH}$, Baines JD. RNA polymerase II Promoter Proximal Pausing and

8. Rutkowski AJ, Erhard F, L'Hernault A, Bonfert T, Schilhabel M, Crump C, et al.

Widespread disruption of host transcription termination in HSV-1 infection. Nat http://www.ncbi.nlm.nih.gov/pubmed/25989971

9. McSwiggen DT, Hansen AS, Teves SS, Marie-Nelly H, Hao Y, Heckert AB, et al. separation. Elife. 2019 Apr 1;8.

10. Wang X, Hennig T, Whisnant AW, Erhard F, Prusty BK, Friedel CC, et al. Herpes simplex virus blocks host transcription termination via the bimodal activities of ICP27. http://www.nature.com/articles/s41467-019-14109-x

11. Zaborowska J, Baumli S, Laitem C, O’Reilly D, Thomas PH, O'Hare P, et al. Herpes Simplex Virus 1 (HSV-1) ICP22 Protein Directly Interacts with Cyclin-Dependent Kinase (CDK)9 to Inhibit RNA Polymerase II Transcription Elongation. Yenugu S, editor. PLoS One [Internet]. 2014 Sep 18 [cited 2020 Jan 13];9(9):e107654. Available from: https://dx.plos.org/10.1371/journal.pone.0107654 
polymerase II is phosphorylated by a complex containing cdk9 and infected-cell protein 22 of herpes simplex virus 1. J Virol [Internet]. 2005 Jun [cited 2018 Nov 30];79(11):6757-62. Available from:

http://www.ncbi.nlm.nih.gov/pubmed/15890914

13. Fraser KA, Rice SA. Herpes Simplex Virus Immediate-Early Protein ICP22 Triggers Loss of Serine 2-Phosphorylated RNA Polymerase II. J Virol [Internet]. 2007 [cited 2019 May 7];81(10):5091-101. Available from:

14. Wiesel Y, Sabath N, Shalgi R. DoGFinder: A software for the discovery and quantification of readthrough transcripts from RNA-seq. BMC Genomics. 2018 Aug 8;19(1):1-7.

15. Giannakakis A, Zhang J, Jenjaroenpun P, Nama S, Zainolabidin N, Aau MY, et al. upon oxidative stress. Sci Rep. 2015 May 29;5.

16. Vilborg A, Passarelli MC, Yario TA, Tycowski KT, Steitz JA. Widespread Inducible Transcription Downstream of Human Genes. Mol Cell. 2015 Aug 6;59(3):449-61. analysis reveals genomic features of stress-induced transcriptional readthrough. Proc Natl Acad Sci U S A. 2017 Oct 3;114(40):E8362-71.

18. Cardiello JF, Goodrich JA, Kugel JF. Heat Shock Causes a Reversible Increase in RNA Polymerase II Occupancy Downstream of mRNA Genes, Consistent with a Global Loss in Transcriptional Termination. Mol Cell Biol [Internet]. 2018 Jul 2 [cited 2018 Sep 
transcription read-through promotes aberrant expression of oncogenes and RNA chimeras in renal carcinoma. Elife. 2015 Nov 17;4(NOVEMBER2015).

20. Hennig T, Michalski M, Rutkowski AJ, Djakovic L, Whisnant AW, Friedl M-S, et al. HSV1-induced disruption of transcription termination resembles a cellular stress response but selectively increases chromatin accessibility downstream of genes. PLoS Pathog. $2018 ; 14(3)$.

21. Harlen KM, Trotta KL, Smith EE, Mosaheb MM, Fuchs SM, Churchman LS. Comprehensive RNA Polymerase II Interactomes Reveal Distinct and Varied Roles for Each Phospho-CTD Residue. Cell Rep. 2016 Jun 7;15(10):2147-58.

22. Hsin JP, Sheth A, Manley JL. RNAP II CTD phosphorylated on threonine-4 is required for histone mRNA 3' end processing. Science (80- ). 2011 Nov 4;334(6056):683-6.

23. Hintermair C, Heidemann M, Koch F, Descostes N, Gut M, Gut I, et al. Threonine-4 of mammalian RNA polymerase II CTD is targeted by Polo-like kinase 3 and required for transcriptional elongation. EMBO J. 2012 Jun 13;31(12):2784-97.

24. Yurko N, Liu X, Yamazaki T, Hoque M, Tian B, Manley Correspondence JL. MPK1/SLT2 Links Multiple Stress Responses with Gene Expression in Budding Yeast by Jan 13];68:913-925.e3. Available from: https://doi.org/10.1016/j.molcel.2017.11.020 reveals genome-wide nascent transcription coupled to RNA processing. Cell. 2015;161(3).

26. Voss K, Forné I, Descostes N, Hintermair C, Schüller R, Maqbool MA, et al. Site-specific 602 methylation and acetylation of lysine residues in the C-terminal domain (CTD) of RNA polymerase II. Transcription. 2015 Oct 20;6(5):91-101. 
604

605

606

607

608

609

610

611

612

613

614

615

616

617

618

619

620

621

622

623

624

625

626

627

27. Dubois M-F, Bellier S, Seo S-J, Bensaude O. Phosphorylation of the RNA Polymerase II Largest Subunit During Heat Shock and Inhibition of Transcription in Hela Cells. J Cell Physiol [Internet]. 1994 Mar [cited 2019 Aug 8];158(3):417-26. Available from: http://doi.wiley.com/10.1002/jcp.1041580305

28. Venetianer A, Dubois M-F, Nguyen VT, Bellier S, Seo S-J, Bensaude O. Phosphorylation State of the RNA Polymerase II C-Terminal Domain (CTD) in Heat-Shocked Cells. Possible Involvement of the Stress-Activated Mitogen-Activated Protein (MAP) Kinases. Eur J Biochem [Internet]. 1995 Oct 1 [cited 2019 Aug 8];233(1):83-92. Available from: http://doi.wiley.com/10.1111/j.1432-1033.1995.083_1.x

29. Dubois M-F, Marshall NF, Nguyen VT, Dahmus GK, Bonnet F, Dahmus ME, et al. Heat shock of HeLa cells inactivates a nuclear protein phosphatase specific for dephosphorylation of the C-terminal domain of RNA polymerase II [Internet]. Vol. 27, Nucleic Acids Research. 1999 [cited 2020 Jan 13]. Available from: https://academic.oup.com/nar/article-abstract/27/5/1338/2902213

30. Yakovchuk P, Goodrich JA, Kugel JF. B2 RNA represses TFIIH phosphorylation of RNA polymerase II. Transcription. 2011;2(1):45-9.

31. Schreieck A, Easter AD, Etzold S, Wiederhold K, Lidschreiber M, Cramer P, et al. RNA polymerase II termination involves C-terminal-domain tyrosine dephosphorylation by CPF subunit Glc7. Nat Struct Mol Biol. 2014 Feb 12;21(2):175-9.

32. Shah N, Maqbool MA, Yahia Y, El Aabidine AZ, Esnault C, Forné I, et al. Tyrosine-1 of RNA Polymerase II CTD Controls Global Termination of Gene Transcription in Mammals. Mol Cell. 2018 Jan 4;69(1):48-61.e6.

33. Rice SA, Long MC, Lam V, Spencer CA. RNA polymerase II is aberrantly phosphorylated and localized to viral replication compartments following herpes 
34. Long MC, Leong V, Schaffer PA, Spencer CA, Rice SA. ICP22 and the UL13 protein subunit of RNA polymerase II. J Virol [Internet]. 1999 Jul [cited 2017 Aug 14];73(7):5593-604. Available from: http://www.ncbi.nlm.nih.gov/pubmed/10364308

35. Zhou C, Knipe DM. Association of Herpes Simplex Virus Type 1 ICP8 and ICP27 Proteins with Cellular RNA Polymerase II Holoenzyme. J Virol [Internet]. 2002 Jun 15 [cited 2017 Aug 4];76(12):5893-904. Available from: http://jvi.asm.org/cgi/doi/10.1128/JVI.76.12.5893-5904.2002

36. Dai-Ju JQ, Li L, Johnson LA, Sandri-Goldin RM. ICP27 interacts with the C-terminal domain of RNA polymerase II and facilitates its recruitment to herpes simplex virus 1 transcription sites, where it undergoes proteasomal degradation during infection. J Virol [Internet]. 2006 Apr [cited 2017 Aug 6];80(7):3567-81. Available from: http://www.ncbi.nlm.nih.gov/pubmed/16537625 specifically required for expression of herpes simplex virus 1 replication-dependent late genes. J Biol Chem. 2017;292(37):15489-500.

38. Li L, Johnson LA, Dai-Ju JQ, Sandri-Goldin RM. Hsc70 Focus Formation at the Periphery of HSV-1 Transcription Sites Requires ICP27. Jin D-Y, editor. PLoS One [Internet]. 2008 Jan 30 [cited 2020 Jan 9];3(1):e1491. Available from: 
Dec 27 [cited 2020 May 4];11(1):2038. Available from:

http://www.nature.com/articles/s41467-020-15992-5

655

40. Hay J, Köteles GJ, Keir HM, Subak Sharpe H. Herpes virus specified ribonucleic acids.

Nature [Internet]. 1966;210(5034):387-90. Available from:

657

https://www.nature.com/nature/journal/v210/n5034/pdf/210387b0.pdf

658

41. Flanagan JF. Virus-specific Ribonucleic Acid Synthesis in KB Cells Infected with Herpes

[cited 2020 Jan 13]. Available from: http://jvi.asm.org/

661

42. Spencer CA, Dahmus ME, Rice SA. Repression of host RNA polymerase II transcription

662

by herpes simplex virus type 1. J Virol [Internet]. 1997 Mar [cited 2017 Aug

663

6];71(3):2031-40. Available from: http://www.ncbi.nlm.nih.gov/pubmed/9032335

664

43. Jenkins HL, Spencer CA. RNA Polymerase II Holoenzyme Modifications Accompany

665

Transcription Reprogramming in Herpes Simplex Virus Type 1-Infected Cells. J Virol

666

667

[Internet]. 2001 Oct 15 [cited 2017 Aug 4];75(20):9872-84. Available from:

http://jvi.asm.org/cgi/doi/10.1128/JVI.75.20.9872-9884.2001

668

44. Burch AD, Weller SK. Nuclear Sequestration of Cellular Chaperone and Proteasomal

Machinery during Herpes Simplex Virus Type 1 Infection. J Virol. 2004 Jul

670 $1 ; 78(13): 7175-85$.

671

45. Adlakha M, Livingston CM, Bezsonova I, Weller SK. The HSV-1 immediate early protein ICP22 is a functional mimic of a cellular J-protein. J Virol [Internet]. 2019 Nov 20 [cited 2020 Jan 16]; Available from: 
676

677

678

679

680

681

682

683

684

685

686

687

688

689

690

691

692

693

694

695

696

697

698

699

(VICE) domains function as nuclear protein quality control centers during HSV-1 infection. PLoS Pathog. 2009;5(10).

47. Durand LO, Roizman B. Role of cdk9 in the optimization of expression of the genes regulated by ICP22 of herpes simplex virus 1. J Virol [Internet]. 2008 Nov 1 [cited 2019 May 7];82(21):10591-9. Available from:

http://www.ncbi.nlm.nih.gov/pubmed/18753202

48. Tufegdžić Vidaković A, Mitter R, Kelly GP, Neumann M, Harreman M, RodríguezMartínez M, et al. Regulation of the RNAPII Pool Is Integral to the DNA Damage Response. Cell. 2020;

49. Akhrymuk I, Kulemzin S V., Frolova El. Evasion of the Innate Immune Response: the Old World Alphavirus nsP2 Protein Induces Rapid Degradation of Rpb1, a Catalytic Subunit of RNA Polymerase II. J Virol. 2012 Jul 1;86(13):7180-91.

50. Kim ET, Dybas JM, Kulej K, Reyes ED, Price AM, Akhtar LN, et al. Comparative proteomics identifies Schlafen 5 (SLFN5) as a herpes simplex virus restriction factor that suppresses viral transcription. Nat Microbiol. 2021;

51. Ou M, Sandri-Goldin RM. Inhibition of cdk9 during Herpes Simplex Virus 1 Infection Impedes Viral Transcription. Leib DA, editor. PLoS One [Internet]. 2013 Oct 18 [cited 2019 May 3];8(10):e79007. Available from:

https://dx.plos.org/10.1371/journal.pone.0079007

52. Alfonso-Dunn R, Arbuckle JH, Vogel JL, Kristie TM. Inhibition of the super elongation complex suppresses herpes simplex virus immediate early gene expression, lytic infection, and reactivation from latency. MBio. 2020 May 1;11(3):1-14.

53. Gu B, Eick D, Bensaude O. CTD serine-2 plays a critical role in splicing and termination factor recruitment to RNA polymerase II in vivo. Nucleic Acids Res. 2013; 
700

701

702

703

704

705

706

707

708

709

710

711

712

713

714

715

716

717

718

719

720

721

722

723

54. Egloff S, O’Reilly D, Chapman RD, Taylor A, Tanzhaus K, Pitts L, et al. Serine-7 of the RNA polymerase II CTD is specifically required for snRNA gene expression. Science (80- ). 2007 Dec 14;318(5857):1777-9.

55. Scherer KM, Manton JD, Soh TK, Mascheroni L, Connor V, Crump CM, et al. A fluorescent reporter system enables spatiotemporal analysis of host cell modification during herpes simplex virus-1 replication. J Biol Chem. 2021;

56. Bugai A, Quaresma AJC, Friedel CC, Lenasi T, Düster R, Sibley CR, et al. P-TEFb Activation by RBM7 Shapes a Pro-survival Transcriptional Response to Genotoxic Stress. Mol Cell. 2019 Apr 18;74(2):254-267.e10.

57. Tian B, Zhao Y, Kalita M, Edeh CB, Paessler S, Casola A, et al. CDK9-Dependent Transcriptional Elongation in the Innate Interferon-Stimulated Gene Response to Respiratory Syncytial Virus Infection in Airway Epithelial Cells. J Virol. 2013 Jun $15 ; 87(12): 7075-92$.

58. Suh H, Ficarro SB, Kang UB, Chun Y, Marto JA, Buratowski S. Direct Analysis of Phosphorylation Sites on the Rpb1 C-Terminal Domain of RNA Polymerase II. Mol Cell. 2016 Jan 21;61(2):297-304.

59. Guo L, Wu W juan, Liu L ding, Wang L chun, Zhang Y, Wu L qiu, et al. Herpes Simplex Virus 1 ICP22 Inhibits the Transcription of Viral Gene Promoters by Binding to and Blocking the Recruitment of P-TEFb. PLoS One [Internet]. 2012 Sep 24 [cited 2021 Jun 22];7(9):31100127. Available from: http://www.973.gov.cn/

60. Hong H, Zeng Y, Jian W, Li L, Lin L, Mo Y, et al. CDK7 inhibition suppresses rheumatoid arthritis inflammation via blockage of NF-KB activation and IL-1ß/IL-6 secretion. J Cell Mol Med. 2018;

61. Wei Y, Li C, Bian H, Qian W, Jin K, Xu T, et al. Targeting CDK7 suppresses super 
enhancer-linked inflammatory genes and alleviates CAR T cell-induced cytokine release syndrome. Mol Cancer. 2021;

62. Egloff S, Zaborowska J, Laitem C, Kiss T, Murphy S. Ser7 phosphorylation of the CTD recruits the RPAP2 ser5 phosphatase to snRNA genes. Mol Cell. 2012;

63. Egloff S, Szczepaniak SA, Dienstbier M, Taylor A, Knight S, Murphy S. The integrator complex recognizes a new double mark on the RNA polymerase II carboxyl-terminal domain. J Biol Chem [Internet]. 2010 Jul 2 [cited 2019 Aug 8];285(27):20564-9. Available from: http://www.ncbi.nlm.nih.gov/pubmed/20457598

64. Rosa-Mercado NA, Zimmer JT, Apostolidi M, Rinehart J, Simon MD, Steitz JA. Hyperosmotic stress alters the RNA polymerase II interactome and induces readthrough transcription despite widespread transcriptional repression. Mol Cell. 2021;

65. Tietjen JR, Zhang DW, Rodríguez-Molina JB, White BE, Akhtar MS, Heidemann M, et

al. Chemical-genomic dissection of the CTD code. Nat Struct Mol Biol. 2010;

66. Czudnochowski N, Bösken CA, Geyer M. Serine-7 but not serine-5 phosphorylation primes RNA polymerase II CTD for P-TEFb recognition. Nat Commun. 2012;

67. Bösken CA, Farnung L, Hintermair C, Schachter MM, Vogel-Bachmayr K, Blazek D, et al. The structure and substrate specificity of human Cdk12/Cyclin K. Nat Commun. 2014;

68. DeLuca NA, Schaffer PA. Physical and functional domains of the herpes simplex virus transcriptional regulatory protein ICP4. J Virol [Internet]. 1988 Mar [cited 2019 Dec 13];62(3):732-43. Available from: http://www.ncbi.nlm.nih.gov/pubmed/2828668 
25. Available from:

750

https://www.ncbi.nlm.nih.gov/pmc/articles/PMC191683/pdf/714614.pdf

751

70. Smith IL, Hardwicke MA, Sandri-Goldin RM. Evidence that the herpes simplex virus immediate early protein ICP27 acts post-transcriptionally during infection to regulate gene expression. Virology [Internet]. 1992 Jan [cited 2018 May 25];186(1):74-86. Available from: http://www.ncbi.nlm.nih.gov/pubmed/1309283

71. Roberts APE, Abaitua F, O'Hare P, McNab D, Rixon FJ, Pasdeloup D. Differing Roles of Inner Tegument Proteins pUL36 and pUL37 during Entry of Herpes Simplex Virus Type 1. J Virol. 2009 Jan 1;83(1):105-16.

72. Abaitua F, Hollinshead M, Bolstad M, Crump CM, O'hare P. A Nuclear Localization Signal in Herpesvirus Protein VP1-2 Is Essential for Infection via Capsid Routing to the Nuclear Pore. 2012 [cited 2019 Dec 13]; Available from: http://jvi.asm.org/.

73. Sandbaumhüter M, Döhner K, Schipke J, Binz A, Pohlmann A, Sodeik B, et al. Cytosolic herpes simplex virus capsids not only require binding inner tegument protein pUL36 but also pUL37 for active transport prior to secondary envelopment. Cell Microbiol [Internet]. 2013 Feb [cited 2018 May 25];15(2):248-69. Available from: http://www.ncbi.nlm.nih.gov/pubmed/23186167

74. Stow ND, Stow EC. Isolation and characterization of a herpes simplex virus type 1 mutant containing a deletion within the gene encoding the immediate early polypeptide Vmw110. J Gen Virol. 1986;67(12):2571-85.

75. Post LE, Roizman B. A generalized technique for deletion of specific genes in large genomes: a gene 22 of herpes simplex virus 1 is not essential for growth. Cell. 
772 76. Samaniego LA, Neiderhiser L, Deluca NA. Persistence and Expression of the Herpes Simplex Virus Genome in the Absence of Immediate-Early Proteins [Internet]. Vol. 72, JOURNAL OF VIROLOGY. 1998 [cited 2019 Dec 13]. Available from: http://jvi.asm.org/

775 77. Schindelin J, Arganda-Carreras I, Frise E, Kaynig V, Longair M, Pietzsch T, et al. Fiji: An open-source platform for biological-image analysis. Vol. 9, Nature Methods. 2012. p. 676-82. 


\section{Supporting Information}

780 S1 Fig. Measurement of RPB1 CTD serine phosphorylation after exposure to stress using

different antibodies. Human foreskin fibroblasts were subjected to mock treatment (lane 1), significant differences to mock are indicated as $* p<0.05, * * p<0.01, * * * p<0.001$.

immediate-early gene mutants. (A) Human foreskin fibroblast (HFF) cells infected with HSVcycloheximide reversal (SWAP; $4 \mathrm{~h}$ CHX followed by $8 \mathrm{~h}$ ActD) and total protein analysed at $12 \mathrm{~h}$ RPB1 were resolved on 3-8\% Tris-Acetate gels to better capture lower molecular weight degradation products. (B) HFF cells infected with indicated HSV-1 mutants at MOI 10 for $1 \mathrm{~h}$, and inoculum replaced with growth media or media containing phosphonoacetic acid (PAA) for $8 \mathrm{~h}$. Total protein was harvested and levels of pS2, pS7, and RPB1 analyzed by Western 
801 for ICP22 ( $\Delta 22)$, ICP4 $(\Delta 4)$, ICP27 $(\Delta 27)$, and ICPO $(\Delta 0)$. (C) Quantification of Western blots

802 described in (B). Means of at least three biological replicates for PAA-treated samples are plotted with standard errors. Statistically significant differences to mock are indicated as * $p$ $<0.05, * * p<0.01$ cropping irrelevant samples.

S4 Fig. Quantification of RPB1 levels after stress using different antibodies. Human foreskin fibroblasts were subjected to heat $\left(44^{\circ} \mathrm{C}, 2 \mathrm{~h}\right), \mathrm{HSV}-1$ infection (strain $17 \mathrm{syn}+, \mathrm{MOI} 10$, $8 \mathrm{~h}$ p.i.), high salt $(80 \mathrm{mM} \mathrm{KCl}, 1 \mathrm{~h})$, and arsenite $(0.5 \mathrm{mM} \mathrm{NaAsO}, 1 \mathrm{~h})$ treatment and total protein harvested at the end of the stress period. Quantification of RPB1 was performed using the

820 listed antibodies via Western blotting and normalizing to Vinculin levels on the same membrane. Plotted are the means of three biological replicates with standard deviations with representative Western blots to the right. 
824 S5 Fig. RPB1 serine CTD phosphorylation and viral replication in HSV-1-infected RPB1

825 K1268R cells. Clonal cell lines D12 and E2 bearing the RPB1 K1268R mutation and parental

826 wild-type (WT) 293T cells were infected with HSV1(17+)-LoxCheVP26 expressing the VP26

827 viral late gene fused to mCherry and harvested at $8 \mathrm{~h}$ p.i. (A) Representative Western blots of

828 CTD serine phosphorylations from data graphed in Fig 3. (B) Viral gene expression at analyzed

829 timepoints is comparable across cell lines as viewed by live-cell imaging of mCherry-VP26

830 fusion protein. (C) Time-course of HSV-1 strain 17+ production from an initial infection of MOI

831 0.01. Plotted are the means of two replicates with standard deviations. PFU, plaque-forming

832 units; ND, no plaques detected for this timepoint; LOD, statistical limit of detection defined

833 by 10 plaques at lowest dilution.

834

835 S6 Fig. Comparison of RPB1 levels in the amanitin-based replacement assay. Cells treated in

836 parallel for the RPB1 replacement assay described in Fig 5 were harvested at the time of

837 infection and probed for total CTD levels, the HA tag from the trans-expressed RPB1

838 constructs, and vinculin as a housekeeping gene.

839

840 S1 Table. Antibodies used in this study.

841

842 Figure captions 
Fig 1. Western blot quantification of RPB1 CTD modifications in primary human fibroblasts

844 during conditions of polyA-site read-through.

845 (A) Human foreskin fibroblasts were subjected to heat $\left(44^{\circ} \mathrm{C}, 2 \mathrm{~h}\right), \mathrm{HSV}-1$ infection (strain

$84617 \mathrm{syn}+, \mathrm{MOI} 10,8 \mathrm{~h})$, osmotic $(80 \mathrm{mM} \mathrm{KCl}, 1 \mathrm{~h})$, and oxidative $\left(0.5 \mathrm{mM} \mathrm{NaAsO}_{2}, 1 \mathrm{~h}\right)$ stress and

847 total protein harvested at the end of the stress period. Samples were resolved by SDS-PAGE

848 and probed for levels of RPB1, its CTD modifications, and vinculin as a housekeeping control.

849 Signal for each CTD modification was measured, normalized to the signal for total RPB1 on

850 the same blot, and plotted relative to levels in untreated cells. (B) Mean values of three

851 biological replicates with standard deviations are plotted. Statistically significant differences

852 to mock are indicated as $* p<0.05, * * p<0.01$.

853

854 Fig 2. Loss of CTD serine 7 phosphorylation in HSV-1 infection requires immediate-early

855 proteins ICP22 and ICP27.

856 (A) Human foreskin fibroblasts (HFF) were infected with HSV-1 17syn+ with and without DNA

857 replication inhibitor phosphonoacetic acid (PAA) and total protein harvested at given

858 timepoints. Levels of CTD serine 7 phosphorylation (pS7) relative to total RPB1 were

859 quantified by Western blotting. (B) Means of at least three replicates relative to the

860 corresponding mock-infected sample plotted with standard deviations. (C) HFF cells infected

861 with HSV-1 KOS treated with PAA or KOS-derived mutants lacking the combinations of

862 immediate-early genes indicated in the table in the bottom right. White bars indicate removal

863 of irrelevant samples. Total protein was harvested at $8 \mathrm{~h}$ p.i. and pS2/7 levels probed by

864 Western blot. (D) Quantification of phospho-serine normalized to total RPB1. Means of three 
replicates normalized to mock-infected samples with PAA with standard error are plotted, values from KOS are from PAA-treated samples. Statistically significant differences to mock are indicated as $* p<0.05, * * p<0.01$ induced RPB1 remodeling.

871 (A) Human foreskin fibroblasts were infected with HSV-1 17syn+ and treated with indicated

872 proteasome inhibitors for $8 \mathrm{~h}$ before collection of total protein and quantification of CTD Ser2

873 and Ser7 phosphorylation by Western blotting. Plotted are means of two replicates with

874 standard deviations. (B-D) 293T parental wild-type (WT) and clonally derived RPB1 K1268R

875 mutant cell lines were infected with HSV1(17+)-LoxCheVP26 and total RPB1 or

876 phosphorylated CTD serine residues quantified by Western blotting. (B) Relative levels of CTD

877 serine phosphorylation at 8 p.i.; plotted are three individual replicates with longest lines

878 indicating means and shortest standard error ranges. (C) Representative Western blot of RPB1

879 levels in uninfected (Un.) 293T WT and RPB1 K1268R or cells infected for 8 and 24h. (D)

880 Relative RPB1 levels normalized to vinculin in infected 293T WT and RPB1 K1268R cells;

881 plotted are means of at least three replicates with standard error. 
Fig 4. Co-localization of RPB1 CTD modifications with viral replication compartments.

884 Human foreskin fibroblasts were infected with HSV-1 strain 17syn+ for 8 h before fixation.

885 Antibody staining was performed for viral protein ICP4, RPB1, and its respective CTD 886 modifications. $p=$ phosphorylation, me=methylation.

887

888 Fig 5. CTD serine 2, but not serine 7, is required for efficient viral gene expression.

889 HEK-293T cells were co-transfected with a construct expressing Azurite blue fluorescent 890 protein as a transfection marker and plasmids expressing amanitin-resistant RPB1 with wild-

891 type (WT) or indicated mutant CTDs, or the control vector pcDNA3 lacking any polymerase.

892 The next day, $\alpha$-amanitin was added to degrade endogenous RPB1 for $24 \mathrm{~h}$ followed by

893 infection with an eYFP-ICP0-/gC-mCherry-expressing HSV-1. Live-cell imaging was performed

894 at $24 \mathrm{~h}$ p.i. All images were acquired with the same settings, with infection of untransfected,

895 amanitin-untreated cells included as a reference for the relative level of viral gene expression.

896 PC: phase contrast, S2A: serine 2 to alanine, S7A: serine 7 to alanine, S7E: serine 7 to

897 glutamate. Scale bars indicate $100 \mu \mathrm{m}$. 


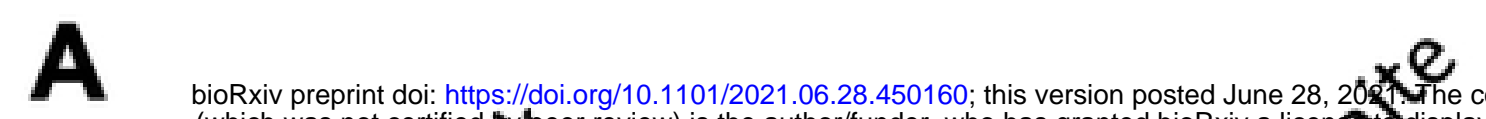

Inder forthilis prepoint

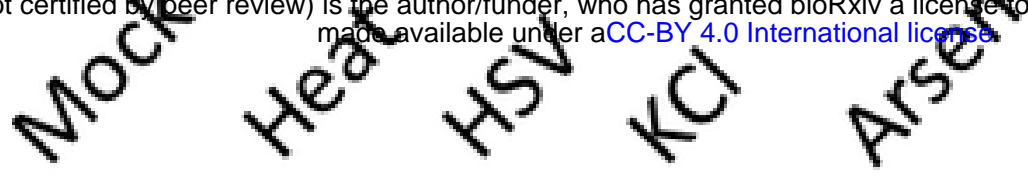

RPB1

-Ilo

- Ili

- Ila

pS2

pY1

pS5

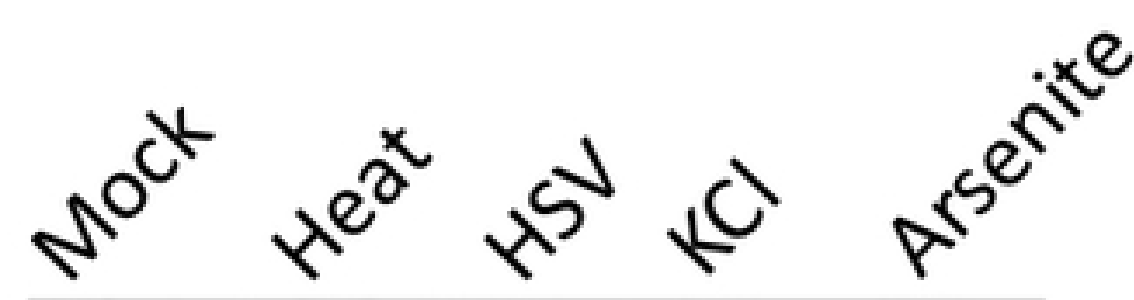

pT4
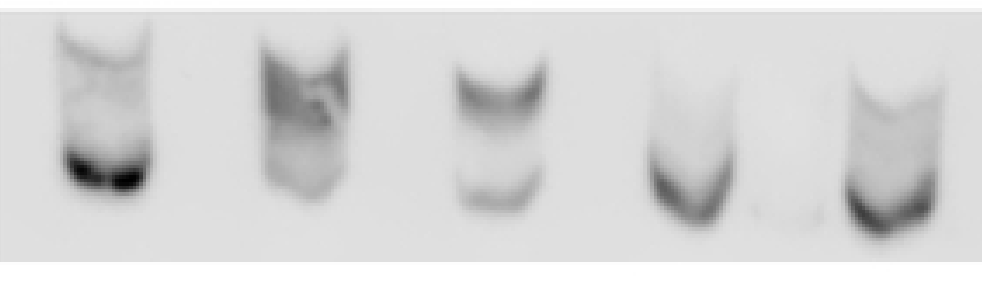

$\mathrm{K} 7 \mathrm{me} 2 / 3$

Vinculin

B
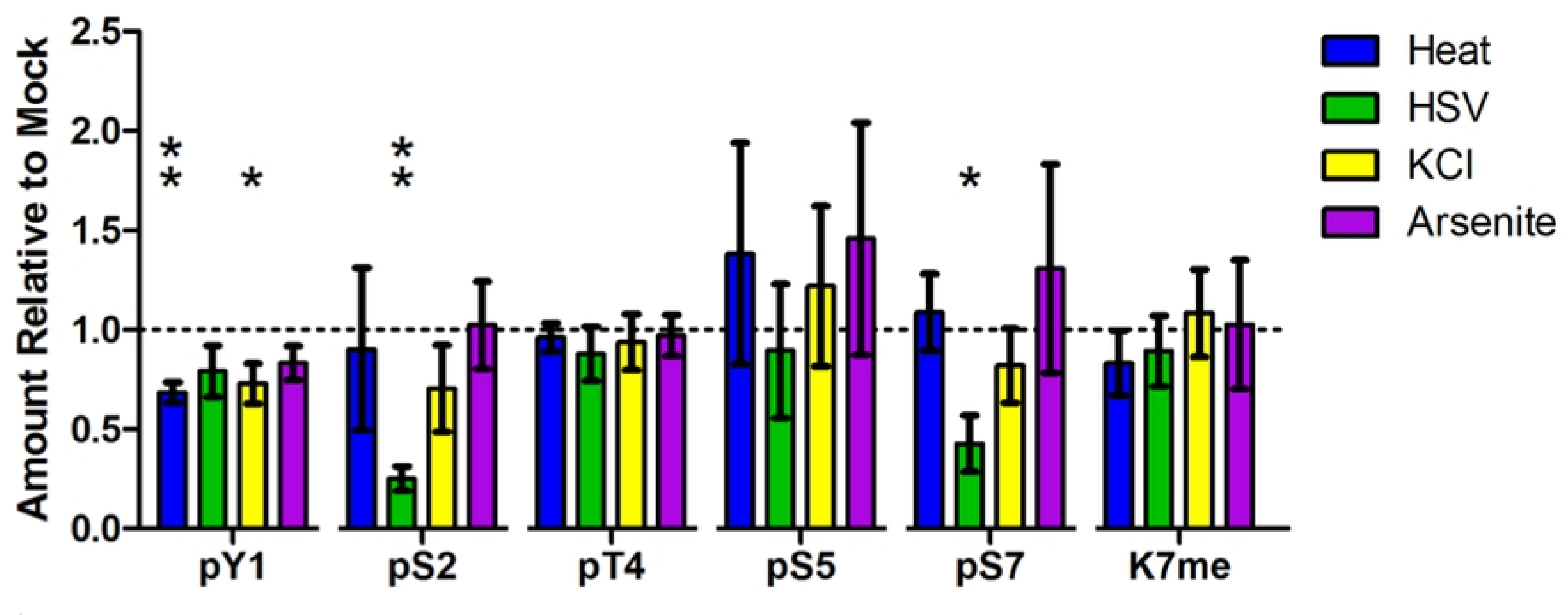

pS7
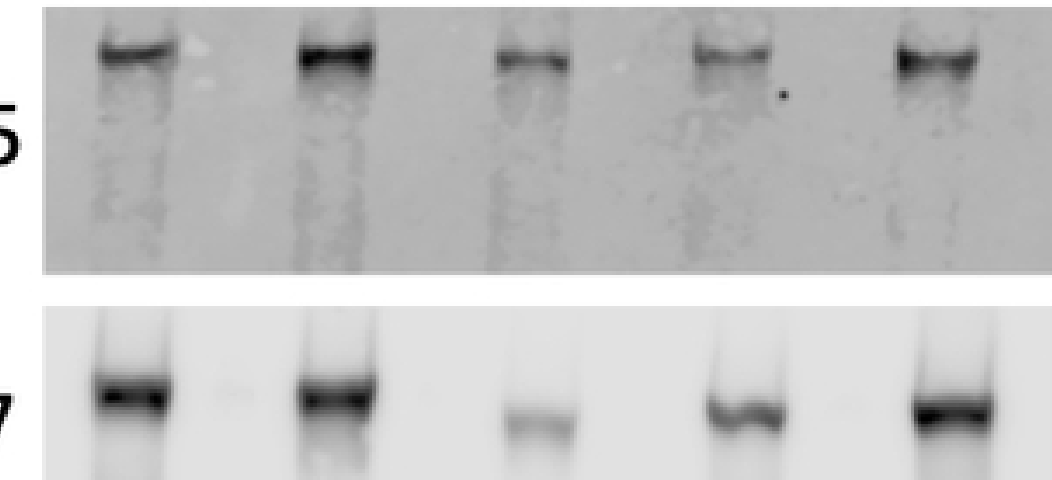

Figure 1 
A
PAA: $\frac{\text { Uninf. }}{-+} \frac{2 \mathrm{hpi}}{-+} \frac{4 \mathrm{hpi}}{-+} \frac{6 \mathrm{hpi}}{-+} \frac{8 \mathrm{hpi}}{-+}$
pS7
RPB1

C

pS2

RPB1

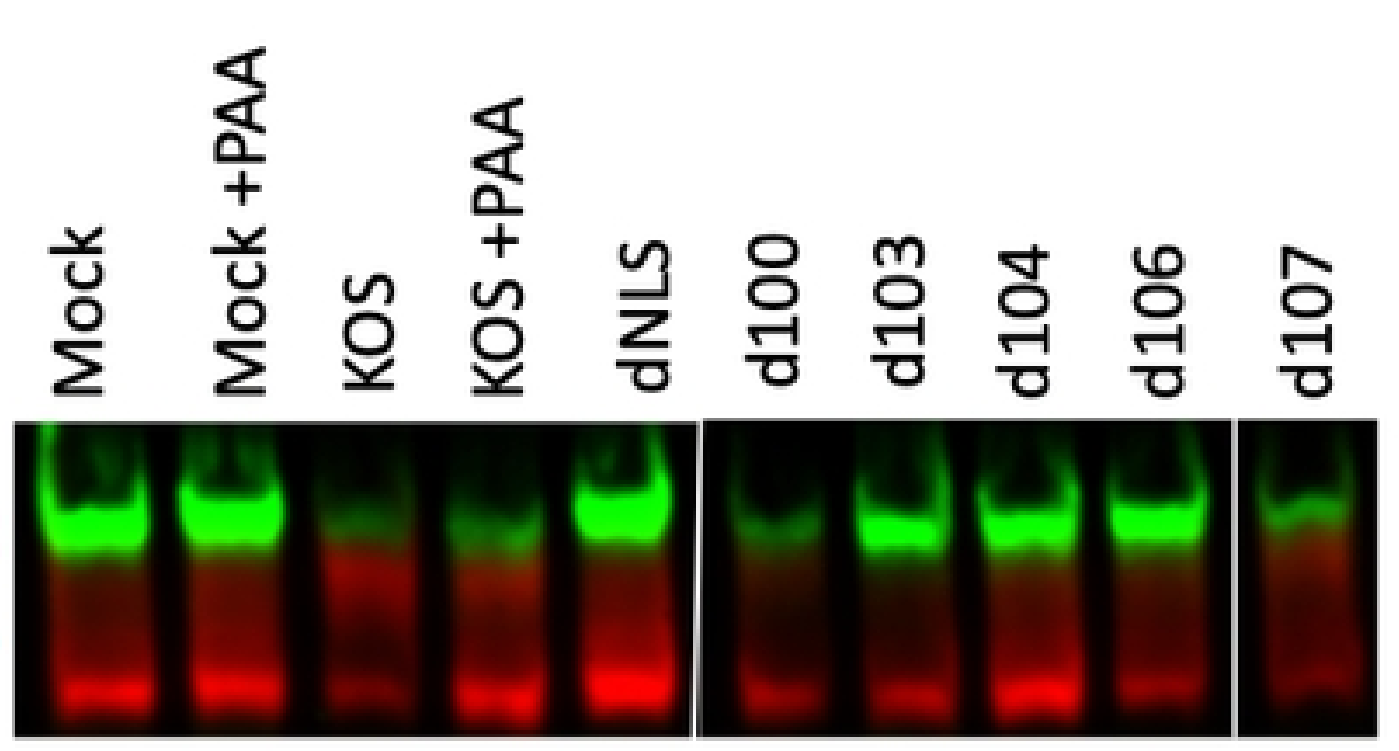

pS7
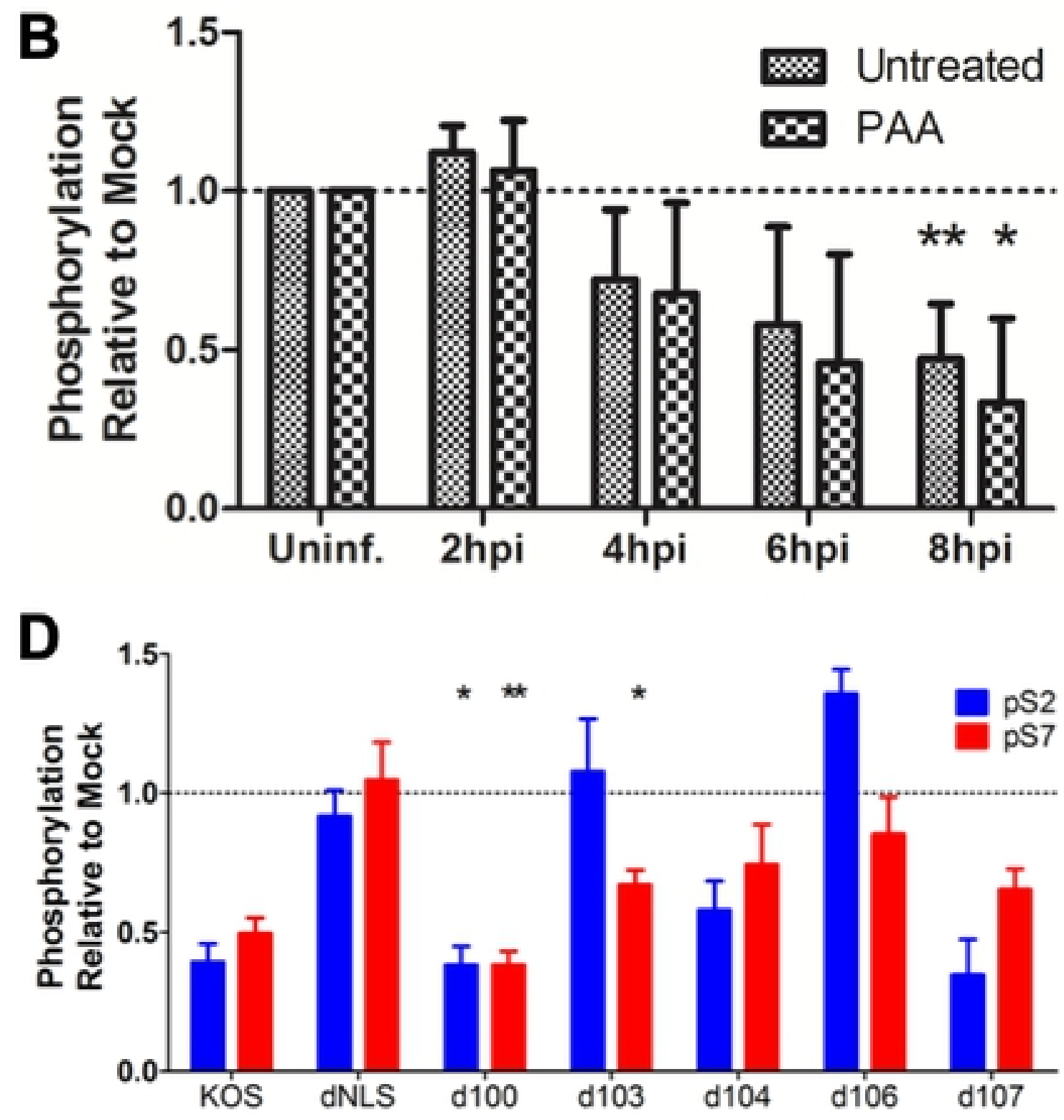

Figure 2 


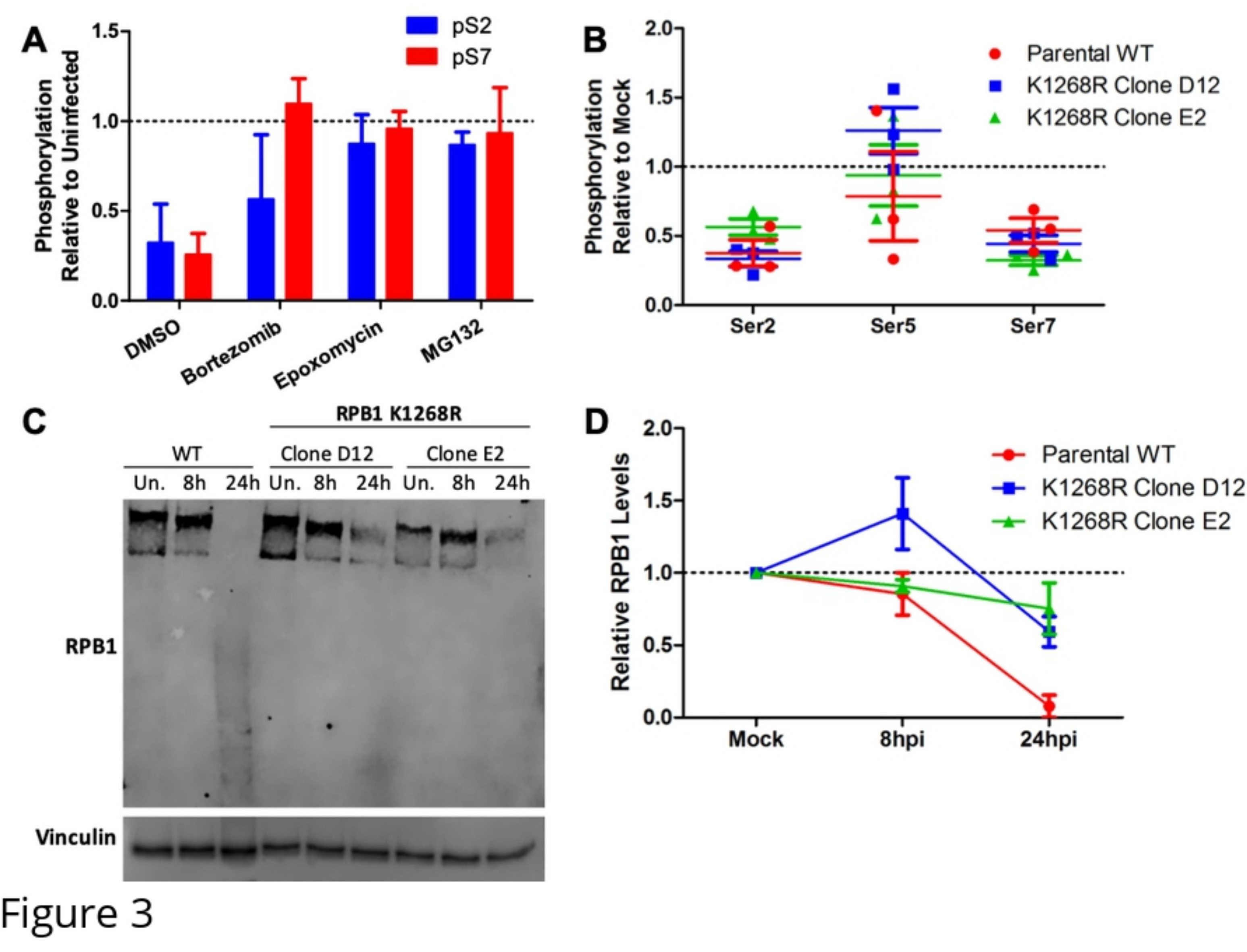




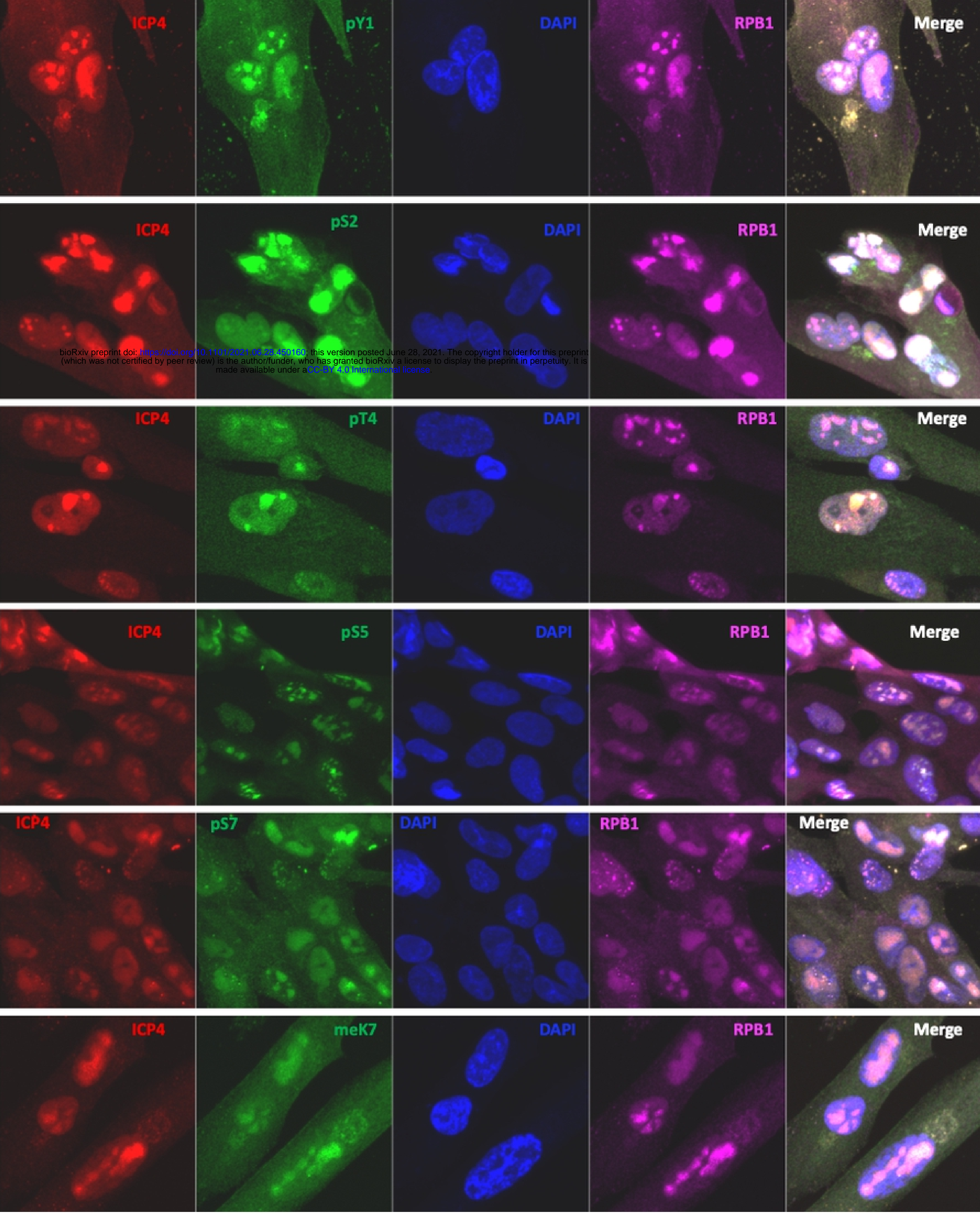

Figure 4 
